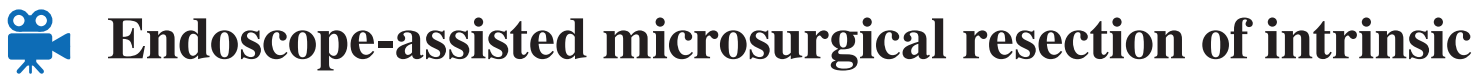 brainstem epidermoid: technical note and review of the literature
}

\begin{abstract}
Alan R. Cohen, MD, ${ }^{1}$ and Scellig S. D. Stone, MD, $\mathrm{PhD}^{2}$
'Department of Neurosurgery, The Johns Hopkins University School of Medicine, Baltimore, Maryland; and 2Department of Neurosurgery, Boston Children's Hospital, Harvard Medical School, Boston, Massachusetts

Intrinsic epidermoid tumors of the brainstem are rare, histologically benign lesions associated with high surgical morbidity and mortality due to their eloquent location. The authors report a child with progressive severe neurological deterioration from a large midline intrinsic brainstem epidermoid at the pontomedullary junction. The mass was removed through a posterior fossa craniotomy and midline endoscope-assisted microsurgical corridor through the floor of the fourth ventricle, using neurophysiological monitoring. Postoperatively, there was dramatic improvement in the patient's symptoms. Early recurrence of the mass necessitated reoperation with more aggressive resection of the cyst capsule, which led to complete radiographic reconstitution of the brainstem. The patient remains well with a durable recovery 7 years after presentation. The authors review the literature on brainstem epidermoids and discuss the differential diagnosis and management strategies for approaching these lesions, advocating for conservative surgery with resection of as much of the tumor capsule as is safely possible.
\end{abstract}

https://thejns.org/doi/abs/10.3171/2020.6.PEDS20482

KEYWORDS brainstem; brain tumor; epidermoid; microsurgery; MRI; neuroendoscopy; diagnosis; oncology; surgical technique

$\mathrm{I}$ NTRACRANIAL epidermoids are rare, representing $0.2 \%$ $1.8 \%$ of all intracranial tumors. ${ }^{1-3}$ They are generally found in the basal subarachnoid cisterns, and their most common intracranial location is the cerebellopontine angle (CPA), followed by the parasellar region., ${ }^{4,5}$ Epidermoids account for approximately $5 \%$ of all masses in the CPA and are the third most common tumor in this location, after vestibular schwannomas and meningiomas. ${ }^{6}$

Intracranial epidermoids are even more rare in the pediatric population, and brainstem epidermoids in children are extremely uncommon, with only scattered case reports in the literature, particularly in the MRI era. Of the reported cases in the past 20 years, only 13 were purely intrinsic brainstem epidermoids ${ }^{1,3,7-14}$ In this paper, we describe our experience with the diagnosis and successful management of a large, complex, symptomatic midline intrinsic brainstem epidermoid of the pontomedullary junction in a 2.5-year-old child, and review the literature on this benign but treacherous lesion.

\section{Case Report History}

This 2.5-year-old girl presented to the pediatric neurosurgery clinic with progressive neurological decline over 3 months. She first developed lethargy and vomiting. Her hands were tremulous and she had trouble with coordination. Her speech became soft and slurred and her mother could no longer understand what she was saying. She held her mouth open and began gagging. She was unsteady while walking and her gait became progressively worse, such that she was no longer able to ambulate independently. Her oral intake was poor and episodic vomiting persisted. During this period, she had been evaluated four times by local physicians in the office or in emergency rooms. Thyroid function tests were sent and returned normal. She was referred for further evaluation.

\section{Examination}

Upon examination she was awake but irritable and

ABBREVIATIONS CISS = constructive interference in steady state; $\mathrm{CPA}=$ cerebellopontine angle; $\mathrm{DWI}=$ diffusion-weighted imaging; $\mathrm{OR}=$ operating room . SUBMITTED June 3, 2020. ACCEPTED June 9, 2020. 
spoke in a soft voice with a significant nasal dysarthria. The occipitofrontal circumference was $47 \mathrm{~cm}$. Pupils were $2 \mathrm{~mm}$, equal and reactive to light. Extraocular muscles showed weakness of abduction bilaterally. There was a facial diplegia. She was diffusely weak with generalized hypotonia and could ambulate with assistance with a slow, wide-based gait and truncal ataxia.

\section{Neuroimaging}

High-resolution cranial MRI showed a large midline retroclival mass invaginating into the brainstem at the junction of the pons and medulla with a small exophytic component anteriorly. The mass virtually filled the brainstem at this level with only a very thin rim of normal tissue surrounding it. A high-resolution constructive interference in steady state (CISS) MRI sequence showed that posteriorly, the mass came very close to the floor of the fourth ventricle and produced mass effect on the floor, but did not violate it. The mass was hypointense on T1weighted images and hyperintense on T2-weighted images, with a thin rim of patchy gadolinium enhancement but no central enhancement. Diffusion-weighted imaging (DWI) showed significant restriction of diffusion (Fig. 1). There was no hydrocephalus. Cranial CT showed some scalloping of the clivus but no bone deformity.

\section{First Operation}

We selected a posterior fossa trans-fourth ventricle corridor because of the close proximity of the tumor to the fourth ventricle floor and the presence of bilateral sixth and seventh cranial nerve palsies already at the time of presentation. Surgery was performed in the MR/OR suite with the patient prone and the head fixed in pediatric pins. Using frameless stereotactic navigation (Brainlab), we fashioned a midline posterior fossa craniotomy and facilitated exposure of the fourth ventricle between the cerebellar tonsils by opening the cerebellomedullary fissure with a telovelar approach. We used intraoperative neurophysiological monitoring with motor evoked potentials, somatosensory evoked potentials, brainstem auditory evoked potentials, and monitoring of cranial nerves VII-XII bilaterally.

Under microsurgical magnification we could see that the floor of the fourth ventricle was markedly elevated by the underlying mass. The tumor could be seen through a paper-thin area where it came up to the fourth ventricle floor just inferior to the facial colliculi. We made a 6-mm midline opening in this region and evacuated thick milkywhite flaky material using a combination of suction and irrigation. With this technique we were able to collapse the cavity. The neuromonitoring potentials remained intact throughout the procedure.

Next, we inspected the operative cavity by inserting a $0^{\circ}$ 2.2-mm-diameter endoscope lens (Aesculap) through the medullotomy. We confirmed complete removal of the lesion and could see only a clear glistening membrane through which we could identify the brainstem laterally and the vertebrobasilar junction anteriorly. Resection of the lesion was confirmed on intraoperative MRI, with no restriction of diffusion (Fig. 2).
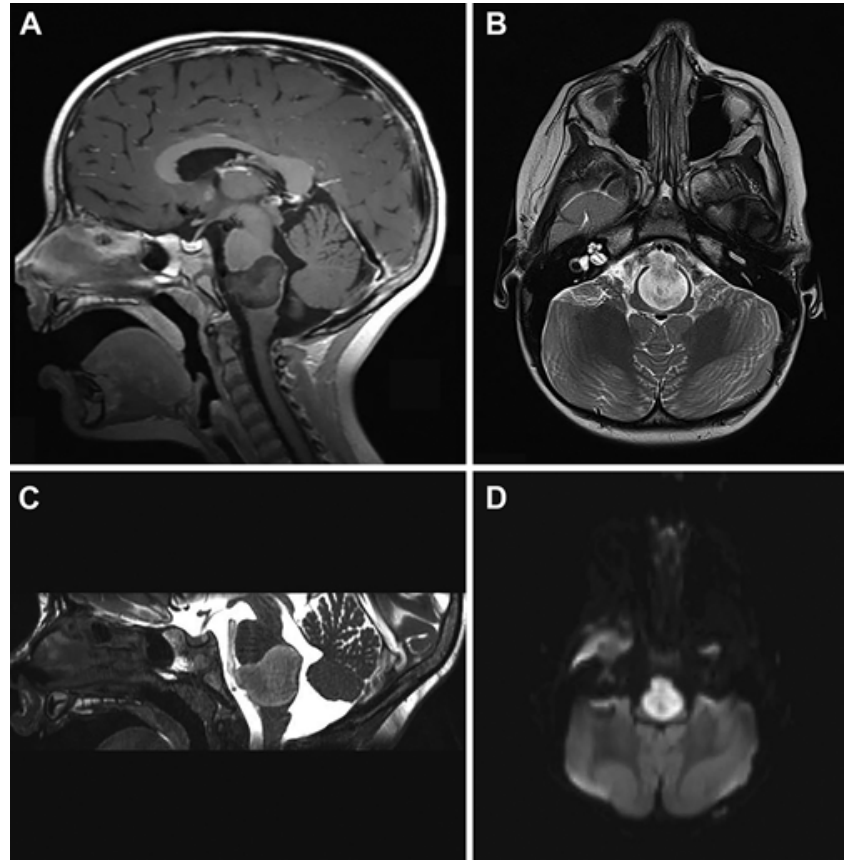

FIG. 1. Preoperative MRI showing a large tumor filling the brainstem at the pontomedullary junction. A: Contrast-enhanced T1-weighted sagittal image. The mass is hypointense without significant enhancement. B: Axial T2-weighted image. The mass is hyperintense and fills the brainstem abutting the vertebral arteries anteriorly. C: Sagittal CISS image showing the mass abutting the floor of the fourth ventricle. D: Axial diffusion-weighted image showing marked restriction of diffusion.

\section{Postoperative Course}

Pathological analysis showed cellular material consistent with an epidermoid tumor. The patient had an uncomplicated course and was discharged in good condition after 1 week. She improved dramatically. One month later, her sensorium was brighter and her speech was clear. She was eating well and gaining weight. Her eyes now moved conjugately and her facial diplegia was completely gone. She smiled frequently. Her strength improved and she was walking independently and even dancing.

Two months postoperatively the patient began to develop gait ataxia followed by slowly progressive deterioration with poor appetite, bilateral esotropias, bilateral facial weakness, and generalized weakness of the limbs. The findings were similar to her initial presentation but not as severe. Lumbar puncture was unremarkable. Repeat MRI 3 months after the first operation showed return of the brainstem mass, almost to the same size as preoperatively (Fig. 3).

\section{Second Operation}

Five months after the first operation the patient underwent repeat posterior fossa craniotomy and endoscopeassisted microsurgical resection of the brainstem lesion in the MR/operating room (OR) suite. We used neurophysiological monitoring, just as was done in the first operation. Again, we found the brainstem expanded by the underlying tumor. We opened the fourth ventricle floor in the midline just inferior to the facial colliculi at the site of our prior medullotomy, this time extending the prior open- 

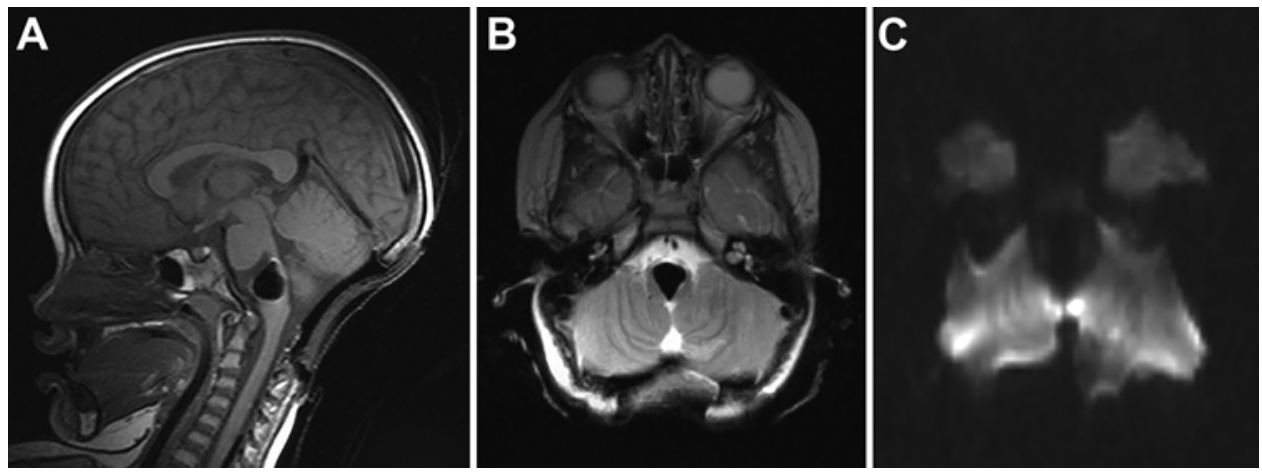

FIG. 2. Sagittal T1-weighted (A), axial T2-weighted (B), and axial diffusion-weighted (C) intraoperative MRI in the MR/OR suite following resection of the brainstem mass showing no residual lesion.

ing $5 \mathrm{~mm}$ more caudally. Again, we were able to remove thickened, off-white flaky material using a combination of suction and irrigation.

The brainstem collapsed and again we entered the medullotomy, this time using $0^{\circ}$ and $30^{\circ}$ angled endoscope lenses. We identified the glistening transparent membrane, but this time we were more aggressive and we removed nonadherent segments of the membrane and made wide fenestrations anteriorly into the subarachnoid space. The patient became transiently bradycardic and hypertensive, but the vital signs normalized after we stopped working for a few minutes. We saw no evidence of residual lesion. Anteriorly we were able to see the vertebrobasilar junction as well as the origin of the anterior spinal artery. Intraoperative MRI confirmed radical resection of the mass, without evidence of hemorrhage, swelling, or hydrocephalus (Fig. 4A).

\section{Second Postoperative Course}

Pathology showed keratinous debris and keratin-positive cells consistent with an epidermoid. This time the patient had a more complicated recovery. She had bilateral sixth nerve palsies and a vertical gaze palsy, along with bilateral facial weakness. She had swallowing difficulty necessitating placement of a temporary gastrostomy tube for feeding.
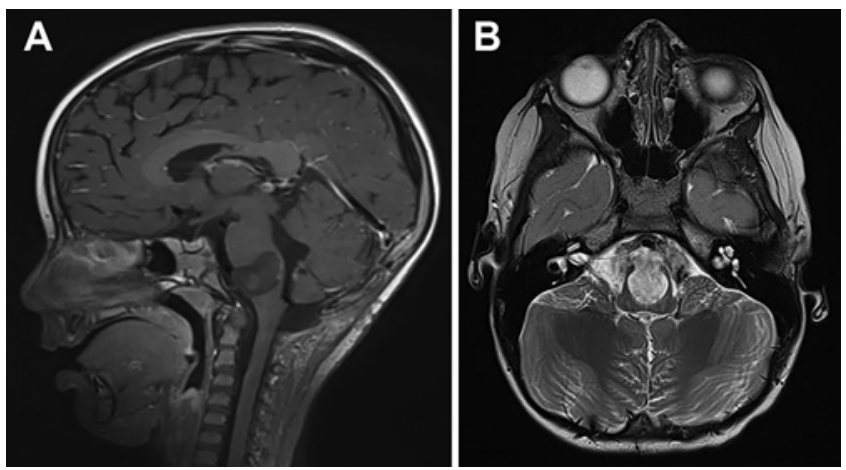

FIG. 3. MRI demonstrating recurrence of the brainstem epidermoid 3 months following resection. A: Contrast-enhanced T1-weighted sagittal image showing early tumor recurrence, almost back to its original size. B: Axial T2-weighted image showing the tumor again filling the brainstem.
She made a slow, steady recovery. Her extraocular movements improved. She was left with mild bilateral esotropias but no diplopia, and her facial weakness resolved after several months. Her swallowing improved and the gastrostomy tube was removed after several months following evaluation by a speech and language pathologist. She continues to take liquids and solids normally. Her dysarthria resolved. Her clinical response has remained durable. Seven years after presentation she is independently ambulatory and is able to dance and run. She has no dysmetria or ataxia and can tandem walk without difficulty. She is doing well in the third grade and is reading at a fifth-grade level. Repeat MRI 13 months after presentation showed reconstitution of the brainstem with no residual or recurrent tumor. Follow-up MRI 7 years after presentation showed no evidence of tumor (Fig. 4B and C).

\section{Discussion}

\section{Background}

Epidermoids were first described in 1829 by the French anatomist and pathologist Jean Cruveilhier, who used the term tumeur perlée (pearly tumor) based on the characteristic smooth, pure-white glistening appearance of the lesion and its resemblance to mother of pearl..$^{15} \mathrm{His}$ index case, from the Hôtel Dieu, the oldest hospital in Paris, was an incidental autopsy finding in a man who died from a blow to the head. ${ }^{16}$ In 1945, Walter Dandy called epidermoids "perhaps the most beautiful tumors in the body."17

\section{Origin and Embryology}

Intracranial epidermoids are benign, slow-growing, congenital neoplasms that arise from ectodermal remnants during closure of the neural groove during the third to fifth weeks of gestation.,18 They are believed to form as the result of incomplete cleavage of neural tissue from cutaneous ectoderm. ${ }^{19-21}$ Infrequently, epidermoids can be acquired lesions that develop following surgery or trauma.

Histologically, epidermoids are characterized by a capsule of avascular stratified keratinized squamous epithelium surrounding desquamated epithelial cells. The keratin can appear in concentric layers along with crystalline flecks of cholesterol and deposits of cheesy material. Epidermoids tend to grow slowly in a nonexponential 

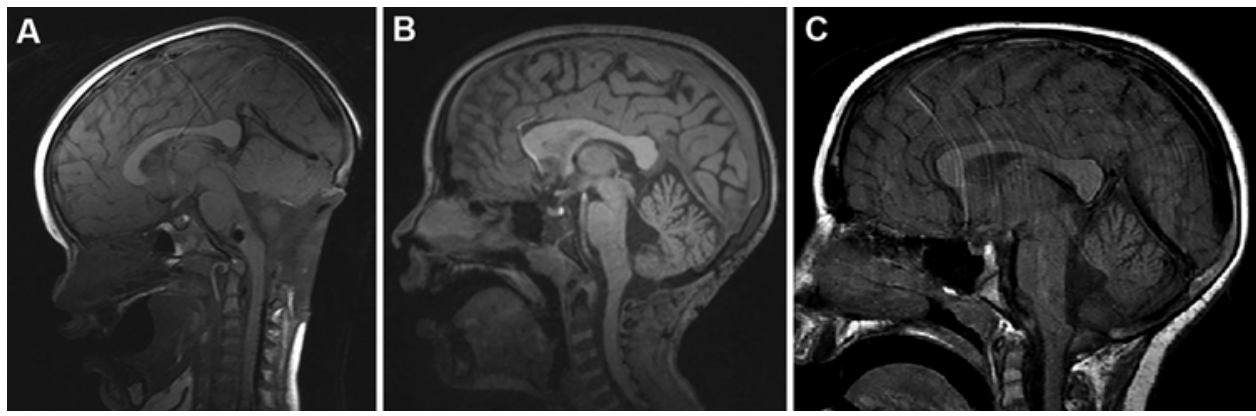

FIG. 4. Sagittal MR images after the second resection of the brainstem epidermoid. A: Intraoperative T2-weighted image in the MR/OR suite immediately following resection of the epidermoid showing no residual lesion. B: T1-weighted image obtained 13 months after presentation showing reconstitution of the brainstem with no recurrent epidermoid. C: T1-weighted image obtained 7 years after presentation showing no recurrence.

linear fashion resulting from the accumulation of cellular debris. ${ }^{2}$ Their growth is rarely neoplastic. They can sometimes be cystic with a milky liquid center. ${ }^{14,22,23}$

\section{Clinical Presentation}

Intracranial epidermoids in adults occur most commonly in the basal cisterns, particularly in the region of the CPA. Although they are considered congenital lesions, they most often become symptomatic between the ages of 20 and 40 years. ${ }^{3,9}$ Symptoms and signs are generally related to cranial nerve, cerebellar, or brainstem dysfunction. ${ }^{2}$ Spillage of irritative cyst contents into the subarachnoid space on occasion can cause aseptic meningitis or hydrocephalus. ${ }^{8,24}$

Brainstem epidermoids are distinctly unique and behave differently than epidermoids of the basal cisterns and other intracranial sites. Brainstem epidermoids occur more commonly in children, with approximately half the lesions reported in the literature in the pediatric population. ${ }^{7}$ Presenting symptoms and signs are related to progressive brainstem compression and include pyramidal tract dysfunction, gait ataxia, and multiple cranial neuropathies.

\section{Differential Diagnosis}

Differential diagnostic considerations for a brainstem epidermoid include neurenteric cyst, arachnoid cyst, abscess, and brainstem glioma. Comprehensive radiographic evaluation is imperative, because the management of each of these lesions is radically different. Intracranial epidermoids tend to be homogeneously hypodense on CT. On MRI, they are usually hypointense on T1-weighted imaging and hyperintense on T2-weighted imaging, without evidence of contrast enhancement. This was true for the lesion in our patient, although we observed patchy peripheral enhancement on MRI. Sometimes the presence of excessive cholesterol crystals and fatty material can lead to a hyperintense (bright) signal on T1-weighted MRI. Epidermoids can be distinguished from arachnoid cysts and other CSF-contained structures on MRI by DWI, with the former characteristically showing significant restriction of diffusion. ${ }^{11,25,26}$

\section{Location}

It is noteworthy that many intrinsic brainstem epider- moids occur at the pontomedullary junction, although the reason for this is unclear. This site is near the sphenooccipital synchondrosis, the cartilaginous junction between the basisphenoid and basioccipital bones that eventually fuse to form the clivus. Because epidermoids are usually congenital lesions, it is intriguing to consider disordered embryogenesis in neural tube formation in their etiology.

As is the case with other anteriorly located congenital lesions such as neurenteric cysts, ectodermal-neural tube dysjunction failure would seem likely to play a role in the formation of brainstem epidermoids. Their medial location is likely related to incomplete separation of cutaneous and neural ectoderm, which occurs in the dorsal midline in embryologic development. ${ }^{19}$ Such a process could lead to the inclusion of heterotopias that appear to be "intrinsic" within the substance of the brainstem. While this may explain the medial location of most intrinsic brainstem epidermoids, it is harder to understand the more common lateral location of epidermoids in the basal cisterns of the CPA. One hypothesis that has been suggested is that with growth there is lateral displacement of ectodermal remnants along the otic vesicles or neurovasculature. ${ }^{2}$ In the present case, we obtained a preoperative CT scan looking for a midline clival abnormality, but were unable to define any defect except for clival scalloping.

It is also worth questioning whether the lesions that are conventionally called intrinsic brainstem epidermoids are truly intraaxial. We were impressed by the anterior exophytic component of the epidermoid in our case and wonder whether these are congenital extraaxial lesions that insinuate themselves into the brainstem as they grow. Unlike the diffuse intrinsic pontine glioma, which is a true intraaxial tumor, the brainstem epidermoid is likely an extraaxial mass that splits the developing brainstem in early embryogenesis. You et al. reported a "split pons syndrome" in 2 adult patients who originally presented with epidermoids of the CPA cisterns. ${ }^{27}$ In each case, the patient had undergone multiple surgeries that likely led to subarachnoid scarring. They suggested that the extraaxial epidermoid followed the path of least resistance to eventually split the anterior pons between the transverse pontocerebellar fibers and slowly encroach posteriorly toward the fourth ventricle. We suspect this represents an acquired form of the congenital "intrinsic" brainstem epi- 

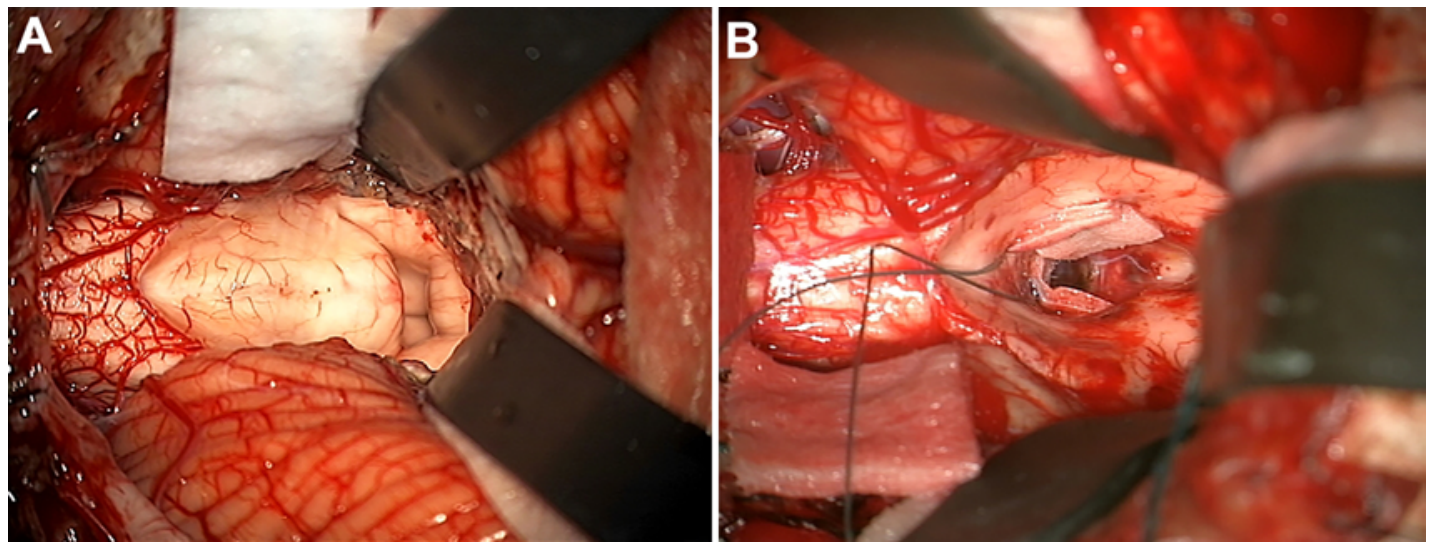

FIG. 5. Microsurgical images showing telovelar exposure into the fourth ventricle, oriented with the caudal/cervicomedullary junction to the left and rostral to the right. A: Initial exposure, first operation. Marked elevation of the floor of the fourth ventricle by the large underlying tumor. By contrast, note the much shallower, normally positioned rostral pons. B: Final exposure, second operation following radical resection of the lesion. Note the opening in the floor of the fourth ventricle with a corridor extending through the center of the brainstem into the anterior subarachnoid space. Figure is available in color online only.

dermoids of childhood, which likely begin as extraaxial masses that invaginate into the developing brainstem.

\section{Surgical Considerations}

The surgical treatment of intrinsic brainstem epidermoids is challenging. The current standard of care is microsurgical resection. ${ }^{4}$ Lesions that are subtotally resected will recur, although favorable outcomes have been described following conservative management.,19,28-30 $\mathrm{Mi}$ crosurgery must be performed thoughtfully, as resection of the entire capsule can sometimes result in devastating neurological injury., ${ }^{79,31-34}$ Even in the microsurgical era, attempts at radical resection of the cyst wall have been associated with high rates of morbidity and mortality. ${ }^{1}$ Novel techniques have been developed to manage some brainstem epidermoids of the ventral cranial base, including endoscopic endonasal surgery as a primary treatment and shunting of cyst contents to the basal cisternal spaces for recurrent lesions. ${ }^{22,31}$ Radiotherapy has been effective in managing selected recurrent intracranial epidermoids in adults, though this would not be a typical treatment modality for young children. ${ }^{35}$

Careful planning is essential to select the safest operative corridor, and intraoperative adjuncts including neuronavigation and neuromonitoring can be helpful. In the present case, the tumor was exophytic anteriorly and we considered transclival or transpetrosal approaches. Ultimately, we selected a midline posterior fossa approach though the fourth ventricle floor because there was one area where the floor was extremely thin, and the patient already had abducens palsies and a facial diplegia at presentation. We were surprised by the dramatic improvement in the sixth and seventh cranial nerve palsies, and suspect they were caused by compression of the facial colliculi.

Our case was unusual because the brainstem epidermoid recurred rapidly after the first operation, with symptoms and signs developing only 2 months after radical removal of the mass. Others have described a rapid increase in the size of these lesions and postulated that it might be due to liquefaction of the cyst contents.7,8,30,36 Our recurrence was confirmed on MRI, which showed that the lesion had returned almost back to its original size in this short time span. We believe the reason for this was that we left much of the cyst capsule in place in the first operation, as it was densely adherent to neurovascular structures of the brainstem. In the second operation, we removed more of the cyst wall, but not all of it, although we were able to open up into the subarachnoid space anterior to the brainstem. This provided a channel through which CSF could flow directly between the subarachnoid space anterior to the brainstem and the fourth ventricle (Fig. 5). At the end of the epidermoid resection and cyst fenestration, we were provided a remarkable endoscopic view of both vertebral arteries seen from a posterior approach through the fourth ventricle and through the corridor that traversed the entire brainstem, from back to front (Fig. 6). The glistening anterior cyst wall and its multiple fenestrations could be seen draping over the vertebral arteries (Video 1).

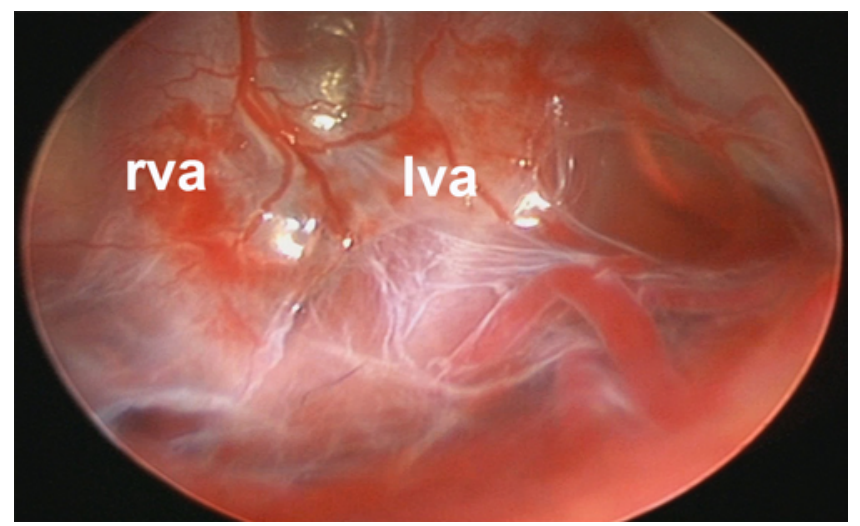

FIG. 6. Endoscopic trans-fourth ventricle view of the vertebrobasilar artery junction. The vertebral arteries are seen from the posterior approach through a corridor that traverses the brainstem, from back to front, after removal of the epidermoid and fenestration of the anterior cyst wall in multiple places. Caudal is superior and rostral is inferior. Iva $=$ left vertebral artery; rva = right vertebral artery. Figure is available in color online only. 

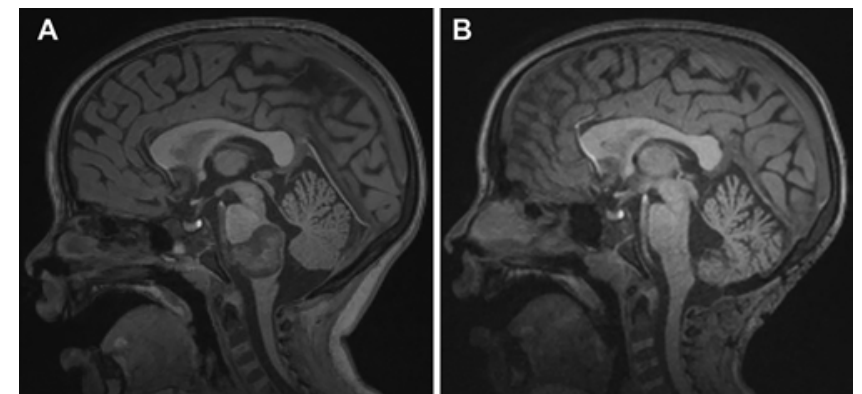

FIG. 7. Reconstitution of the brainstem following radical resection of the intrinsic epidermoid shown on noncontrast T1-weighted sagittal MR images. A: Initial preoperative image showing the epidermoid filling the brainstem at the pontomedullary junction. B: Follow-up image 13 months after presentation showing complete reconstitution of the brainstem and no recurrence. MRI obtained 7 years after presentation from a lowerresolution scanner at an outside institution (Fig. 4C) confirmed a durable response with no late recurrence.

VIDEO 1. Clip showing the endoscopic view of both vertebral arteries following resection of an intrinsic epidermoid at the pontomedullary junction. Multiple fenestrations can be seen in the anterior cyst wall. Near the end of the video, the anterior spinal artery can be seen arising from the medial aspect of the left vertebral artery. Caudal is superior and rostral is inferior. Copyright Alan R. Cohen. Published with permission. Click here to view.

\section{Conclusions}

Intrinsic brainstem epidermoids of childhood are rare histologically benign lesions with a high associated morbidity and mortality due to their eloquent location. The management of symptomatic lesions is surgical, and the surgery is challenging because of their eloquent location and the frequent adherence of the cyst wall to critical neurovascular structures. The authors recommend a strategy of conservative surgery with resection of as much of the tumor capsule as is safely possible (Fig. 7).

\section{References}

1. Fournier D, Mercier P, Menei P, et al. Recurrent intrinsic brain stem epidermoid cyst. Childs Nerv Syst. 1992;8(8): 471-474.

2. Berger MS, Wilson CB. Epidermoid cysts of the posterior fossa. J Neurosurg. 1985;62(2):214-219.

3. Patibandla MR, Yerramneni VK, Mudumba VS, et al. Brainstem epidermoid cyst: an update. Asian J Neurosurg. 2016; 11(3):194-200.

4. Kachhara R, Bhattacharya RN, Radhakrishnan VV. Epidermoid cyst involving the brain stem. Acta Neurochir (Wien). 2000;142(1):97-100.

5. Yoshizato K, Kai Y, Kuratsu J, Ushio Y. Intramedullary epidermoid cyst in the brain stem: case report. Surg Neurol. 1996;45(6):537-540.

6. Bambakidis N, Megerian C, Spetzler R. Surgery of the Cerebellopontine Angle. People's Medical Publishing House; 2009.

7. Caldarelli M, Colosimo C, Di Rocco C. Intra-axial dermoid/ epidermoid tumors of the brainstem in children. Surg Neurol. 2001;56(2):97-105.

8. Gopalakrishnan CV, Dhakoji A, Nair S. Epidermoid cyst of the brainstem in children: case-based update. J Child Neurol. 2012;27(1):105-112.
9. Mishra SS, Panigrahi S, Dhir MK, Pattajoshi AS. Intrinsic brainstem white epidermoid cyst: an unusual case report. $J$ Pediatr Neurosci. 2014;9(1):52-54.

10. Recinos PF, Roonprapunt C, Jallo GI. Intrinsic brainstem epidermoid cyst. Case report and review of the literature. $J$ Neurosurg. 2006;104(4)(suppl):285-289.

11. Singh SK, Jain K, Jain VK. Intrinsic epidermoid of the brain stem: case report and review of the literature. Childs Nerv Syst. 2018;34(8):1589-1592.

12. Takahashi M, Paz Paredes A, Scavarda D, Lena G. Brainstem epidermoid cyst in a child. Case report. Neurol Med Chir (Tokyo). 2007;47(3):140-144.

13. Shtaya A, Dabbous B, Fanou E, et al. Unusual intraparenchymal pontomedullary epidermoid cyst in a 2-year-old child: a case report and review of the literature. World Neurosurg. 2017;104:1046.e15-1046.e20.

14. Mankotia DS, Tandon V, Sardana H, et al. A rare case of white pearls in brainstem. J Pediatr Neurosci. 2016;11(3): 230-233.

15. Bailey P. Cruvelhier's tumeurs perlees. Surg Gynecol Obstet. 1920;31:390-401.

16. Rosenbluth PR, Lichtenstein BW. Pearly tumor (epidermoid cholesteatoma) of the brain. Clinicopathologic study of two cases. J Neurosurg. 1960;17:35-42.

17. Dandy W. The Brain. W.F. Prior; 1945.

18. Yaşargil MG, Abernathey CD, Sarioglu AC. Microneurosurgical treatment of intracranial dermoid and epidermoid tumors. Neurosurgery. 1989;24(4):561-567.

19. Obana WG, Wilson CB. Epidermoid cysts of the brain stem. Report of three cases. J Neurosurg. 1991;74(1):123-128.

20. Ulrich J. Intracranial epidermoids. A study on their distribution and spread. J Neurosurg. 1964;21:1051-1058.

21. Balogun JA, Adeleke NA, Salami AO, Odebode TO. Cerebellar vermian epidermoid tumor: a report of 2 cases. World Neurosurg. 2018;112:153-157.

22. Forbes JA, Banu M, Lehner K, et al. Endoscopic endonasal resection of epidermoid cysts involving the ventral cranial base. J Neurosurg. 2019;130(5):1599-1608.

23. Ziyal IM, Bilginer B, Bozkurt G, et al. Epidermoid cyst of the brain stem symptomatic in childhood. Childs Nerv Syst. 2005;21(12):1025-1029.

24. Schwartz JF, Balentine JD. Recurrent meningitis due to an intracranial epidermoid. Neurology. 1978;28(2):124-129.

25. Mask-Bull L, Do B, Cattaneo JC. Brainstem epidermoid cyst in an individual with two previous intracranial epidermoid cysts: a rare diagnosis in a rare individual. Clin Neurol Neurosurg. 2013;115(9):1888-1890.

26. Tsuruda JS, Chew WM, Moseley ME, Norman D. Diffusionweighted MR imaging of the brain: value of differentiating between extraaxial cysts and epidermoid tumors. AJR Am J Roentgenol. 1990;155(5):1059-1065, 1066-1068.

27. You E, Bokhari R, Sirhan D. Split-pons syndrome by epidermoid cyst: a case report and review of the literature. World Neurosurg. 2019;131:275-280.e10.

28. Iihara K, Kikuchi H, Ishikawa M, Nagasawa S. Epidermoid cyst traversing the pons into the fourth ventricle. Case report. Surg Neurol. 1989;32(5):377-381.

29. Dunn LT, May PL, MacKenzie JM. Brain stem dermoid cyst. Childs Nerv Syst. 1994;10(8):529-532.

30. Weaver EN Jr, Coulon RA Jr. Excision of a brain-stem epidermoid cyst. Case report. J Neurosurg. 1979;51(2):254257.

31. Mortini P, Bailo M, Spina A, et al. Cyst-cisternal shunting for cystic multirecurrent brainstem epidermoid: case report and literature review. Acta Neurochir (Wien). 2016;158(6): 1197-1201.

32. Shimamoto Y, Kawase T, Sasaki H, et al. Anterior transpetrosal approach to the prepontine epidermoids. Skull Base Surg. 1999;9(2):75-80. 
33. Kansal R, Mahore A, Dange N. Giant intramedullary epidermoid extending from the brain stem to the upper thoracic spinal cord. Turk Neurosurg. 2012;22(4):452-453.

34. Malcolm GP, Gibson R, Ironside JW, Whittle IR. Microsurgical excision of a pontomedullary epidermoid cyst with prepontine extension: case report. Neurosurgery. 1996;38(3): 579-583.

35. Morshed RA, Wu SY, Sneed PK, McDermott MW. Radiotherapy for recurrent intracranial epidermoid cysts without malignant transformation: a single-institution case series. $J$ Neurooncol. 2019;144(1):89-96.

36. Leal O, Miles J. Epidermoid cyst in the brain stem. Case report. J Neurosurg. 1978;48(5):811-813.

\section{Disclosures}

The authors report no conflict of interest concerning the materials or methods used in this study or the findings specified in this paper.

\section{Author Contributions}

Conception and design: Cohen. Acquisition of data: both authors. Analysis and interpretation of data: both authors. Drafting the article: Cohen. Critically revising the article: both authors. Reviewed submitted version of manuscript: both authors. Approved the final version of the manuscript on behalf of both authors: Cohen. Study supervision: Cohen.

\section{Supplemental Information \\ Videos}

Video 1. https://vimeo.com/433655894.

\section{Correspondence}

Alan R. Cohen: The Johns Hopkins University School of Medicine, Baltimore, MD. alan.cohen@jhmi.edu. 